\title{
INVESTIGATION OF DOSE-RELATED EFFECTS OF CARNOSINE ON ANXIETY WITH SYMPATHETIC SKIN RESPONSE AND T-MAZE
}

\begin{abstract}
Nazan Dolu', Hale Acer' ${ }^{2}$ Ali Yucel Kara ${ }^{2}$
Erciyes University, Faculty of Medicine, Depart. of Physiology, Kayseri, Turkey'; Erciyes University, Institute of Health Sciences, Department of Physiology, Kayseri, Turkey²

Summary: Carnosine is a dipeptide formed of the amino acids $\beta$-alanine and histidine. Only a limited number of studies have examined the effects of carnosine on sympathetic nerve activation and anxiety. The present study was undertaken to determine the dose-related effects of carnosine on anxiety in the elevated T-maze test (ETM) with electrodermal activity (EDA). Carnosine was injected in three groups of rats with doses of 10 (low dose), 100 (medium dose) and 1000 (high dose) $\mathrm{mg} / \mathrm{kg}$ i.p. Physiological saline was injected in the sham group. The anxiety scores of the rats were measured with ETM 20 minutes after injection. Then, SCL was measured. The decreased number of entries into the open arm (NEOA), the percentage of time spent in the open arm (\% TSOA) and higher EDA [shown by skin conductance level (SCL)] indicate higher anxiety. The NEOA and \% TSOA were lower in the high-dose group than in the other groups. SCL was lower in the medium-dose carnosine group than in the high-dose carnosine and sham groups. SCL was higher in the high-dose group than in the medium-dose and sham groups. Our results suggest that high-dose carnosine produced anxiety-like effects as assessed in the SCL and ETM. Medium-dose carnosine acted as an anxiolytic. The anxiety-related responses of carnosine depend on its dose-related effect.
\end{abstract}

Key words: Carnosine; Sympathetic skin response; Anxiety; Rat; T-maze

\section{Introduction}

Carnosine, a naturally occurruing dipeptide, was first discovered by Gulewitsch and Amiradzibi in a meat extract in 1900 (24). Carnosine ( $\beta$-alanyl-1-histidine), which is a dipeptide formed of the amino acids $\beta$-alanine and histidine, is located in mammalian tissues including those in the central nervous system and in skeletal muscles (22). Carnosine is an endogenously synthesized dipeptide which is present, in particular in the brain, cardiac muscle, kidney, stomach, olfactory bulb and in large quantities in skeletal muscle (18). It is a multifunctional dipeptide with many roles including buffering (7), anti-oxidative properties (6), the activation or inhibition of some enzymes such as phosphorylases (26) and sarcoplasmic reticulum calcium regulation (2).

It is also a powerful anti-inflammatory dipeptide, presumably due to its anti-oxidant and anti-glycation properties (36). Carnosine may prevent aging, Alzheimer's disease and diabetic complications. These conditions are associated with oxidative stress (21).

Only a limited number of studies have examined the effects of carnosine on sympathetic nerve activation. Tanida and Niijima were studied the effect of different doses of carnosine on the blood pressure and renal sympathetic nerve activity (47). As a result of their study, it was found that low-dose carnosine suppressed blood pressure and re- nal sympathetic nerve activity, while high-dose carnosine increased them. On the other hand, we could not find any study in the literature about the anxiogenic or anxiolytic effect of carnosine. In this study, we investigated the effects of different doses of carnosine on anxiety with electrodermal activity (EDA) and elevated T-maze (ETM).

One of the most widely used indices of the autonomic nervous system (ANS) in psychological research has been electrodermal activity (EDA), which is usually measured as skin conductance level (SCL) (10). SCL reflects tonic levels of arousal $(1,8)$. EDA has been utilized in research examining attention (33), emotion (4), and psychopathology (44). It is recorded as a change in skin potential or resistance of sweat gland reaction controlled by the sympathetic nervous system (SNS) (15). The relationship between anxiety and sympathetic skin response (SSR), in other words SCL, has been widely studied. The results of studies on human subjects (shown by higher skin conductance level (SCL) $(5,23$, $11)$ and animals $(12,13)$ indicate that anxious subjects have greater sweat gland activity.

However, data are limited in animals. These studies were conducted to assess the anxiolytic activities of some drugs $(30,41)$, and to measure fear response, anxiety $(12,13)$, arousal (11), and stress (52).

The elevated T-maze test, a well-established animal model of anxiety, is based upon the natural aversion of ro- 
dents to heights and open spaces and has been validated for rats (37). Untreated animals usually spend more time in closed arms. The percentage of time spent in open arms is considered as an index of anxiety $(38,28,45)$. It is generally found that anxiolytic drugs increase the number of entries and time spent in open arms and these are decreased by anxiogenic drugs.

Certain pharmacological compounds can have dose-dependent treatment effects on anxiety-related behavior. The effects of carnosine on anxiety have not been well investigated. We know of only one study examining the relationship between anxiety and beta-alanine (formed in vivo by the degradation of carnosine) (32). According to their study, beta-alanine-supplemented diet increased the percentage of time spent and entries in the open arms significantly in the elevated plus-maze test. This result suggested that chronic ingestion of beta-alanine-supplemented diet had an anxiolytic-like effect in mice. Beta-alanine has also been suggested to act as an inhibitory neurotransmitter, as it was reported to act on GABA and Gly receptors (51). With respect to amino acids, GABA and its receptor agonists had an anxiolytic- and antidepressant effect (32). Especially noradrenaline (NA) and 5-hydroxytriptamine (5-HT), which are thought to be deeply involved in the aetiology of depression and anxiety.

The present study was undertaken for the following reasons: a) to explore whether carnosine effect on anxiety or not $b$ ) to determine the dose-related effects of carnosine on anxiety on the ETM and with EDA, c) to determine the relationship between the behavioral scores of rats tested on the ETM and with EDA, d) which mechanisms may take role of carnosine on anxiety.

\section{Materials and Methods}

\section{Subject}

The experiments were carried out daily on 40 male Wistar rats at the 120-140 between 12:00 and 14:00 hrs. The rats weighed 280-300 g. The animals were acclimatized to the laboratory conditions for one week before the start of the experiment and were kept in a quiet temperature controlled room $\left(22 \pm 4^{\circ} \mathrm{C}\right)$. A 12-hour light-dark cycle $(7: 00$ to $19: 00,19: 00$ to $7: 00$ ) was provided. All rats were bred at the Hakan Çetinsaya Experimental and Clinical Research Center of Erciyes University and were fed with tap water and purina rodent chow. The experiments were carried out after receiving approval from the Committee on Ethics in Animal Experimentation at Erciyes University (no. 08-12-86). All animal experiments were conducted at Erciyes University Faculty of Medicine, Department of Physiology in the Laboratory of Brain Dynamics.

\section{Apparatus and procedure}

Rats were divided randomly into sham and three experimental groups.
1-Sham group $(\mathrm{n}=10)$ : Physiological saline was injected.

2-CAR low-dose group $(\mathrm{n}=10,10 \mathrm{mg} / \mathrm{kg})$ : for preparation of the stock solution, $30 \mathrm{mg}$ carnosine was dissolved in $10 \mathrm{ml}$ physiological saline. Thus, $3 \mathrm{mg} / \mathrm{ml}$ carnosine was administered to each rat (27).

3-CAR medium-dose group $(\mathrm{n}=10,100 \mathrm{mg} / \mathrm{kg})$ : for preparation of the stock solution, $300 \mathrm{mg}$ carnosine was dissolved in $10 \mathrm{ml}$ physiological saline. Thus, $30 \mathrm{mg} / \mathrm{ml}$ carnosine was administered to each rat (28).

4-CAR-high dose group $(\mathrm{n}=10,1000 \mathrm{mg} / \mathrm{kg})$ : for preparation of the stock solution, $3000 \mathrm{mg}$ carnosine was dissolved in $10 \mathrm{ml}$ physiological saline. Thus $300 \mathrm{mg} / \mathrm{ml}$ carnosine was administered to each rat (1).

Carnosine was obtained from Sigma (USA), it was and freshly prepared in saline and given as a single dose i.p. $30 \mathrm{~min}$ before testing.

\section{Elevated T-Maze Test (ETM)}

Rats were also submitted to an ETM, in order to determine if carnosine affected anxiety-related behavior (13). Briefly, the ETM consisted of a central platform $(5 \mathrm{~cm} \times$ $5 \mathrm{~cm})$, with two open arms $(50 \mathrm{~cm} \times 10 \mathrm{~cm} \times 50 \mathrm{~cm})$, and one closed arm $(50 \mathrm{~cm} \times 10 \mathrm{~cm} \times 40 \mathrm{~cm})$. The arms were arranged in such a way that the two both types arms each type were opposite each other. The maze was $50 \mathrm{~cm}$ above floor level and tests were carried out under a dim red light. The animals were placed individually on the central platform of the T-maze facing an open arm. Two observers recorded the number of times spent in the open and closed arms and the number of entries into each arm during a 5 min period. The percentage of time spent in the closed arms and the number of entries into these arms were used as a measure of anxiety.

\section{Electrodermal Activity (EDA)}

The physiological recordings took place in a dimly lit, electrically and acoustically shielded experimental room. EDA was measured using the MP30 system (MP30; Biopac Systems Inc., Santa Barbara, CA). EDA was recorded between the paw pads of both hindllimbs using $2 \mathrm{Ag} / \mathrm{AgCl}$ electrodes after the ETM. $\mathrm{NaCl}$ electrode $(0.05 \mathrm{M})$ jelly was placed between the skin and the electrodes. The two electrodes were connected to the MP30 system. The signals coming from the skin were converted to digital signals by MP30 data acquisition unit and processed for off-line analysis on IBM-AT computer located in a separate room. Digital signals were stored in the computer for data analysis.

The mean of skin conductance (SC) was expressed as $\mathrm{SCL}\left[\ln (\mu \mathrm{mho}) / \mathrm{cm}^{2}\right.$ per electrode area]. Two recordings were taken in 2 sections for all animals.

Tonic section was recorded over 2 min without any stimuli. The phasic section was recorded by giving 15 auditory stimuli. The stimuli were of 1 -s duration, $1000 \mathrm{~Hz}$ tones with $50-\mathrm{ms}$ rise and fall times. The sound chip of a comput- 
er produced the tones. They were amplified with an audio amplifier (Harvard). The intensity of the tones was $90 \mathrm{~dB}$ as measured by a sound level meter positioned at the approximate location of the rat's ear. The tones were presented against a $50-\mathrm{dB}$ pink noise background. They occurred at pseudorandom intervals ranging from $30 \mathrm{~s}$ to $65 \mathrm{~s}$ and averaging $45 \mathrm{~s}$. The mean SCL values were also calculated with off-line for phasic EDA. Values of phasic SCL were averaged from 10 rats per group during the all test period which applied 15 auditory stimuli

\section{Procedure}

The animals were conscious during the recordings. The rat received a single i.p. injection of carnosine or physiological saline. The ETM measurements were started 30 min after the injections. The ETM apparatus was wiped clean with a sponge and dried with cloth between tests. After ETM, SCL was recorded, without losing any time.

\section{Statistical analyses}

Values were expressed as means \pm S.E. Data from the T-maze test and EDA were analyzed with the Kruskal-Wallis test for comparison of the 4 groups and the Mann-Whitney $\mathrm{U}$ test was used for comparison of 2 groups. Differences were considered to be significant with a probability less than 0.05 . All the statistical analyses were performed using the SPSS 16.0 for Windows software.

\section{Results}

\section{Effects of Carnosine on Rats in the T-Maze}

The percentage of time spent and total time in the open arms, and the number of entries into the open and closed arms were measured in the T-maze test. Table 1 shows the performances of the groups in the T-maze. There were significant differences in all parameters according to Kruskal-Wallis test. The NEOA, NECA, TSOA, and \% TSOA values of the sham group were significantly differenct from the CAR groups except for the medium-dose group.

The number of entries into the open arms and percentage of time spent in the open arms were lower in the high-dose group than in the other groups. The CAR-high dose $(1000 \mathrm{mg} / \mathrm{kg})$ decreased the number of open and closed arm entries (respectively, $\mathrm{z}=-3.8, \mathrm{p}<0.000 ; \mathrm{z}=$ $-3.45, \mathrm{p}<0.001)$, times spent in the open arms $(\mathrm{z}=-3.89$, $\mathrm{p}<0.000)$ and percentage of time spent in the open arms $(\mathrm{z}=-3.89 ; \mathrm{p}<0.000)$ when compared to the sham group. This finding indicated that the CAR-high dose exhibited increased anxiety and sympathetic activity.

The CAR-medium dose increased open arm entries and percentage of time spent in the open arms when compared the CAR-high dose.

The CAR-medium dose $(100 \mathrm{mg} / \mathrm{kg})$ increased the number of open arm entries $(z=-2.82, p<0.011)$, the number of enclosed arm entries $(z=-2.49, p<0.013)$, time spent in the open arms $(z=-2.85, p<0.009)$ and percentage of time spent in the open arms $(z=-2.85 ; p<0.009)$, when compared with the CAR-high dose. The anxiolytic potential of CAR-medium dose was stronger than that of other groups in the elevated T-maze model. There was no significant difference between the CAR-medium dose and the sham group.

\section{Effects of Carnosine on Skin Conductance Level}

Table 2 indicates the mean SCL values in all groups. Fig. 1 shows an example phasic EDA recording of the carnosine groups. There were statistical differences among the groups for Tonic SCL (Kruskal-Wallis test, $\mathrm{x}^{2}=13.83$, $\mathrm{p}=$

Tab. 1: Performances of the groups in the T-maze during 5 min period (mean $\pm \mathrm{SE}$ ).

\begin{tabular}{|l|c|c|c|c|}
\hline & NEOA & NECA & TSOA & \% TSOA \\
\hline Sham Group $(\mathrm{n}=10)$ & $1.2 \pm 0.2$ & $2.1 \pm 0.23$ & $38.6 \pm 11.77$ & $12.86 \pm 3.92$ \\
\hline $\begin{array}{l}\text { CAR-low dose } \\
(10 \mathrm{mg} / \mathrm{kg})(\mathrm{n}=10)\end{array}$ & $0.2 \pm 0.13^{* \#}$ & $1.1 \pm 0.1^{* \#}$ & $4.8 \pm 3.21^{* \#}$ & $1.6 \pm 1.07^{* \#}$ \\
\hline $\begin{array}{l}\text { CAR-medium dose } \\
(100 \mathrm{mg} / \mathrm{kg})(\mathrm{n}=10)\end{array}$ & $1.9 \pm 0.5$ & $2.7 \pm 0.49$ & $24.4 \pm 7.15$ & $8.13 \pm 2.38$ \\
\hline $\begin{array}{l}\text { CAR-high dose } \\
(1000 \mathrm{mg} / \mathrm{kg})(\mathrm{n}=10)\end{array}$ & $0.1 \pm 0.1^{* \#}$ & $1.1 \pm 0.1^{* \#}$ & $0.5 \pm 0.5^{* \#}$ & $0.16 \pm 0.16^{* \#}$ \\
\hline $\mathrm{X}^{2}$ & 19.83 & 17.33 & 20.67 & 20.67 \\
\hline $\mathrm{p}$ & $<0.000$ & $<0.000$ & $<0.000$ & $<0.000$ \\
\hline
\end{tabular}

* Different in from sham group.

\# Different in from medium dose group. ( $\mathrm{p}<0.05$; Kruskal-Wallis; post-hoc Mann-Whitney U). NEOA: Number of the entry into open arm; NECA: Number of the entry into closed arm; TSOA: Time spent on open arms; \% TSOA: Percentage of time spent on open arms. 
$0.003)$ and Phasic SCL $\left(x^{2}=13.67, p=0.003\right)$. Tonic and Phasic SCLs were statistically higher in the CAR high-dose group than in the sham group (respectively, $\mathrm{z}=-2.19, \mathrm{p}=$ $0.02 ; \mathrm{z}=-2.04, \mathrm{p}=0.04)$ and the CAR medium-dose group (respectively, $\mathrm{z}=-2.49, \mathrm{p}=0.013 ; \mathrm{z}=-2.26, \mathrm{p}=0.02$ ). Tonic and Phasic SCLs were statistically lower in the CAR medium-dose group than in the sham group (respectively, $\mathrm{z}=-2.49, \mathrm{p}=0.013 ; \mathrm{z}=-2.26, \mathrm{p}=0.02)$ and CAR highdose group (respectively, $\mathrm{z}=-2.49, \mathrm{p}=0.013 ; \mathrm{z}=-2.26$, $\mathrm{p}=0.02$ ). These finding showed that CAR-high dose created an anxiogenic effect, while CAR-medium dose exhibited an anxiolytic effect (Fig. 2).

Tab. 2: Tonic and phasic SCL values of groups (mean $\pm \mathrm{SE}$ ).

\begin{tabular}{|l|c|c|c|}
\hline SCL( $\boldsymbol{\mu m h o )}$ & CAR-low dose $\mathbf{( 1 0} \mathbf{~ m g / k g )}$ & CAR-medium dose (100 $\mathbf{~ m g} / \mathbf{k g})$ & CAR-high dose (1000 $\mathbf{~ m g} / \mathbf{k g})$ \\
\hline Tonic SCL & $9.42 \pm 1.52$ & $6.74 \pm 0.38^{\#}$ & $12.35 \pm 1.21$ \\
\hline Phasic SCL & $8.86 \pm 1.36$ & $6.00 \pm 0.24^{\#}$ & $11.68 \pm 1.32$ \\
\hline
\end{tabular}

* Compared with CAR-medium dose. ${ }^{*}$ Compared with CAR-high dose.

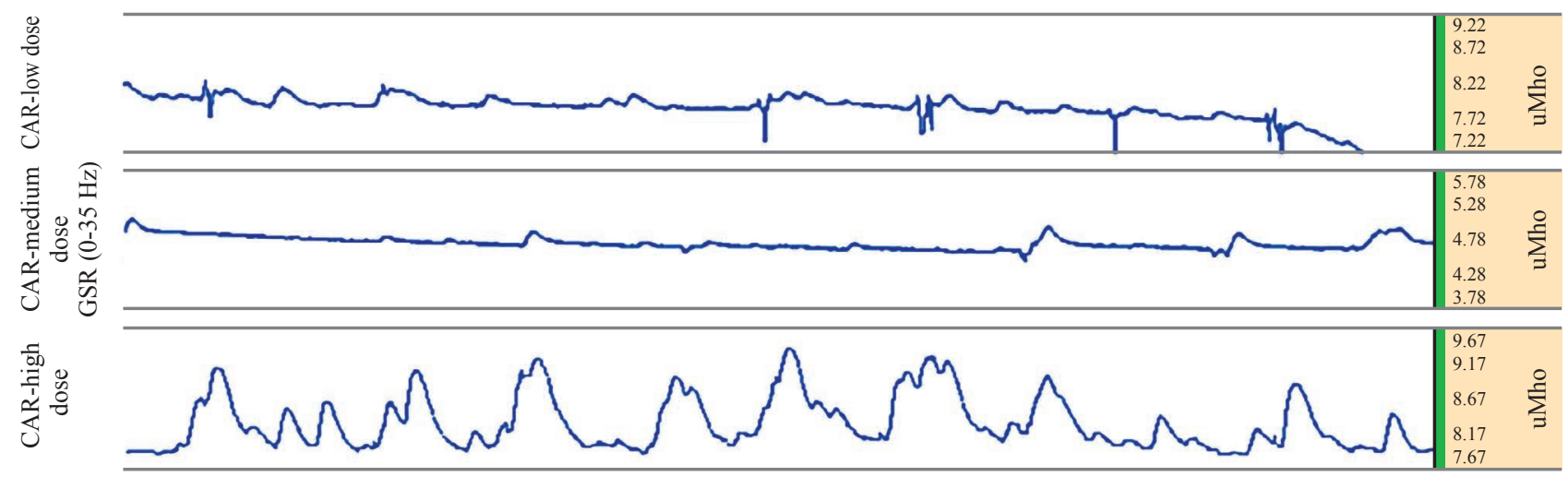

Fig. 1: The phasic EDA recordings of the carnosine groups.

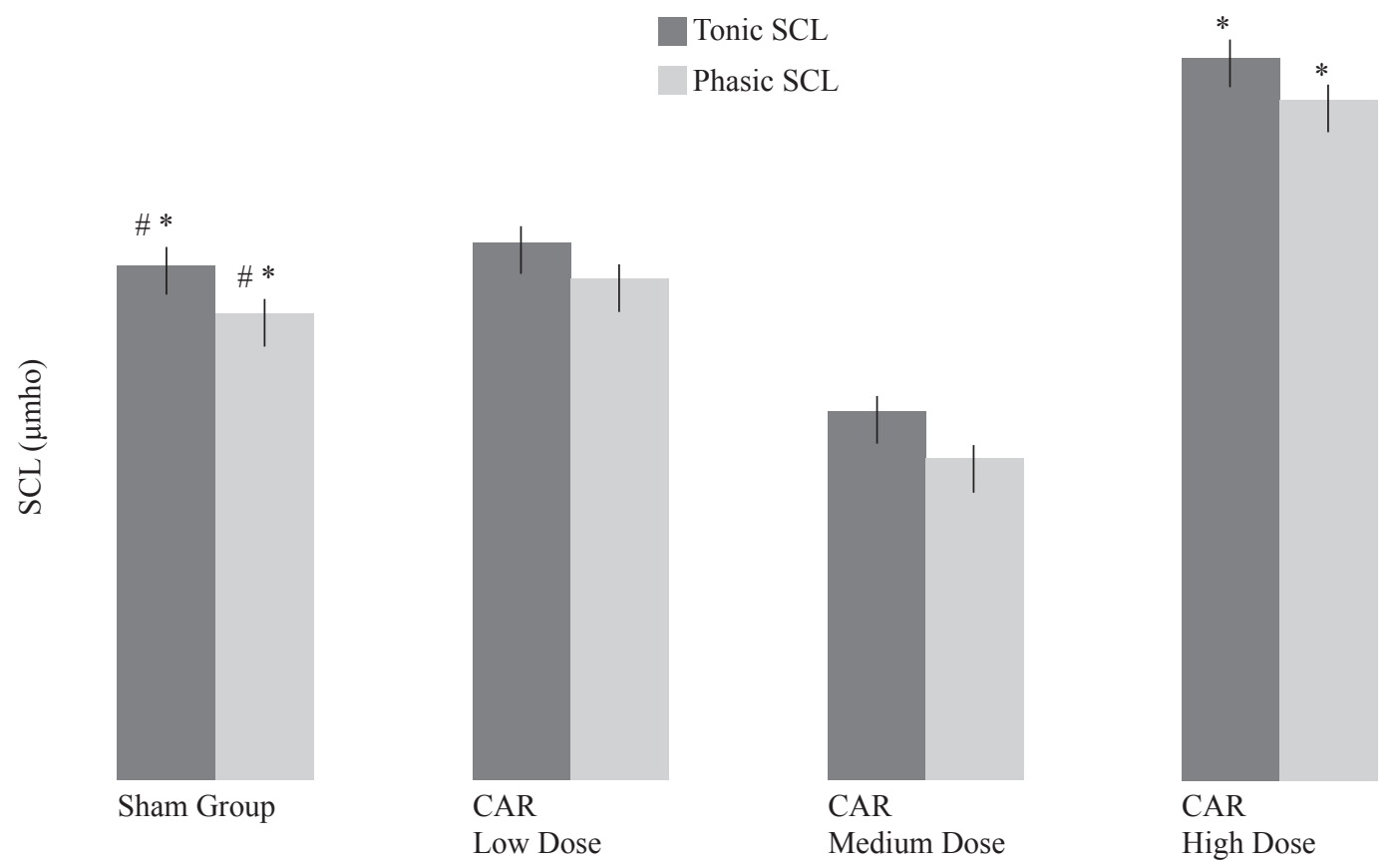

Fig. 2: Comparisons of tonic and phasic SCL values of groups.

* Compared with CAR-medium dose. ${ }^{\#}$ Compared with CAR-high dose. 


\section{Discussion}

Changes in sympathetic nerve activity may produce alterations in physiological functions. In this way, a small amount of CAR generates hypoglycemic, hypotensive, and lipolytic actions, when CAR is released from skeletal muscle (34). The effects of carnosine on blood glucose, BP, lipolysis, and thermogenesis were dose-dependent or bell-shaped. According to the study of Nagai et al., studies (2012), optimal concentrations of CAR in the blood or brain may exist to determine the functions of CAR on these parameters. They claimed that physiologically there is no need to attain the highest CAR concentration in the blood or brain to realize its actions of CAR on these parameters $(35,34)$.

In this study, we investigated the effects of three doses of carnosine (low, medium, high) on sympathetic skin response and anxiety with electrodermal activity and T-maze. We observed decreased anxiety and sympathetic skin response when medium doses of carnosine were injected but increased anxiety and sympathetic skin response when higher doses were injected.

Several studies related to the biphasic action of carnosine have been conducted. Jin et al. showed that long-term treatment with a low histamine diet enhances seizure development induced by PTZ kindling, while this effect can be reversed by simultaneous treatment with a high carnosine diet (25).

Tanida et al. reported that L-carnosine, a dipeptide produced in skeletal muscle, has the biphasic effects on renal sympathetic nerve activity (RSNA) and blood pressure (BP). According to their study, thioperamide inhibited the suppressive effects of a low dose of L-carnosine on RSNA and BP and diphenhydramine eliminated the enhancement of the response caused by a high dose of L-carnosine on RSNA (47). They suggested that that the effect of L-carnosine may be realized via a histaminergic neural function in the brain. It was also reported that carnosine (via histidine) may be metabolically transformed into histamine. In another study, carnosine has been proposed to provide a nonmast cell source of histidine in many histamine-rich tissues, available for histamine synthesis during periods of physiological stress (16).

Tanida et al. studied the biphasic effect of carnosine on brown adipose tissue sympathetic nerve activity (BAT-SNA) in urethane-anesthetized rats (48). The effect of a small or large amount of CAR on interscapular BAT-SNA was the opposite of its effect on white adipose tissue sympathetic nerve activity (WAT-SNA) (43). A small amount of CAR (0.01 mg / $300 \mathrm{~g} \mathrm{BW,} \mathrm{LCV)} \mathrm{suppressed} \mathrm{BAT-SNA,} \mathrm{while}$ a high amount of CAR (100 mg / $300 \mathrm{~g} \mathrm{BW,} \mathrm{LCV)} \mathrm{elevated}$ BAT-SNA (48). They suggested that excitation of BAT-SNA produces an increase in thermogenesis - mainly by using FFA - via activation of the adrenergic b-3 receptor and uncoupling protein 1 (UCP1) (17).

They also examined the effect of CAR on body temperature in unanesthetized rats. The body temperature of rats was lowered by a small amount of CAR $(0.01 \mathrm{mg} / 300 \mathrm{~g}$ $\mathrm{BW}, \mathrm{LCV})$ and elevated by a high amount of CAR (100 mg/ $300 \mathrm{~g} \mathrm{BW}, \mathrm{LCV}$ ) (48). They suggested that a smaller amount of CAR may decrease heat production in the brown adipose tissue (BAT) by suppressing BAT-SNA, whereas a higher amount of CAR increases heat production in BAT by elevating BAT-SNA. They found that these responses were time dependent, and it was possible that they were mediated by the master circadian clock SCN. They found that SCN lesions abolished both changes in autonomic neurotransmission (BAT-SNA) and body temperature, that the SCN was involved in the effect of CAR on BAT-SNA and thermogenesis. According to their study, further studies are required to establish whether the antioxidant and carnosinylation actions of CAR are implicated in the influence of CAR on lipid metabolism and thermogenesis (48).

In our previous study we provided evidence for the biphasic action of carnosine on the dentate gyrus in vivo. We reported that, while lower doses of carnosine decreased population spike amplitude in the dentate gyrus, higher doses had an increasing effect on it. We considered that these findings might have occurred with different processes, such as soluble guanylyl cyclase inhibition or the conversion of carnosine into histamine (46). In the light of these findings we thought that lower doses of carnosine would cause a decrease in intracellular $\mathrm{Ca}^{2+}$ levels by chelate formation with sGS and that a higher dose would cause an increase in intracellular $\mathrm{Ca}^{2+}$ levels by producing histamine-stimulated cAMP production. This explanation also seems to be valid for the SCL data observed in the present study.

Hori et al. examined the effects of intraduodenal (ID) injection of L-carnosine on splenic sympathetic nerve activity (splenic-SNA) in urethane-anesthetized rats. In their study, they applied low-dose carnosine. They found that ID injection of $3.3 \mathrm{mg} / \mathrm{kg}$ of body weight of L-carnosine significantly suppressed splenic-SNA, while $1 \mathrm{mg} / \mathrm{mL}$ of L-carnosine solution given as the only drinking water inhibited tumor proliferation. They suggested that splenic-SNA reduction increases the natural killer (NK) activity of splenic cells, which in turn elevates tumor immunity (22). These results accord with our study.

There are no studies examining the effect of carnosine on anxiety in the literature. Murakami and Furuse investigated the antidepressant or anxiolytic-like effects of taurine and beta-alanine supplemented diet with ETM and forced swimming test. Taurine has functions as a neuromodulator and antioxidant, and beta-alanine (a taurine transporter inhibitor) has a role as a neurotransmitter in the brain (32). Beta-alanine is formed in vivo by the degradation of carnosine and it is also the rate-limiting precursor of carnosine (49). Murakami and Furuse studied behavioral changes and brain metabolites with chronic ingestion of a taurine- $(22.5 \mathrm{mmol} / \mathrm{kg}$ diet $)$ supplemented diet and beta-alanine- $(22.5 \mathrm{mmol} / \mathrm{kg}$ diet $)$ supplemented diet under acute stressful conditions. In the elevated plus maze, significant increases in the percentage of time 
spent in and entries in the open arms were observed in the beta-alanine-supplemented diet fed group compared with taurine-supplemented diet. The beta-alanine-supplemented diet increased carnosine (beta-alanyl-L-histidine) concentration in the cerebral cortex and hypothalamus. They suggested that taurine-supplemented diet had an antidepressant-like effect and the beta-alanine-supplemented diet had an anxiolytic-like effect (32). They did not give the carnosine directly to mice, so we could hot compare our results or our doses with their findings.

Some evidence supports the concept that histaminergic neurons influence anxiety-related behavior via $\mathrm{H} 1$ and $\mathrm{H} 2$ receptor activation $(27,53)$. Serafim et al. (2013) investigated the role of $\mathrm{H} 1$ and $\mathrm{H} 2$ receptors in anxiety. The mice received intraperitoneal injections of saline (SAL), $20 \mathrm{mg} / \mathrm{kg}$ zolantidine (ZOL, an $\mathrm{H} 2$ receptor antagonist), or 8 or $16 \mathrm{mg} / \mathrm{kg}$ chlorpheniramine (CPA, an $\mathrm{H} 1$ receptor antagonist). After $40 \mathrm{~min}$, the animals were subjected to the elevated T-maze (ETM) test. The administration of CPA at the highest dose of $16 \mathrm{mg} / \mathrm{kg}$ decreased the percentage of open arm entries (\%OAE) and the percentage of open arm time (\%OAT) indicating anxiogenic-like behavior. An $8 \mathrm{mg} / \mathrm{kg}$ dose of CPA did not have an effect on anxiety. It has been proposed that histamine modulates the release of acetylcholine via stimulation of $\mathrm{H} 1$ receptors (39). Since acetylcholine may modulate anxiety-related behaviors (9), one may expect that this response to the highest doses of antagonist CPA is mediated through changes in acetylcholine levels. In contrast, other studies have reported an anxiolytic response mediated by $\mathrm{H} 1$ receptors in rats and mice (40). The reported discrepancies could be related to experimental differences among the many factors that appear to influence the aversion to open arms, such as the time of day at which testing occurs (20) and the levels of illumination in the testing room (19).

In conclusion, this is the first study to investigate the effects of carnosine on anxiety and sympathetic skin response. Our results provide evidence for the biphasic action of carnosine on anxiety and sympathetic skin response, while lower doses of carnosine decreased anxiety, higher doses had an increasing effect on it. Although we considered that these findings might have occurred with its conversion into histamine, its anti-oxidant and anti-glycation properties or act on GABA and Gly receptors. Further studies are needed to explain the exact mechanism carnosine has on anxiety and sympathetic activity. After further studies, we are suggesting, carnosine may be important drug for anxiety treatment.

\section{Acknowledgements}

This study was supported by the Research Fund of the Erciyes University (TYL-2013-4284).

Disclosure: The authors declare that they have no conflict of interest.

\section{References}

1. Andor T, Gerlach AL, Rist F. Superior perception of phasic physiological arousal and the detrimental consequences of the conviction to be aroused on worrying and metacognitions in GAD. J Abnorm Psychol 2008; 117: 193-205.

2. Batrukova MA, Rubtsov AM. Histidine-containing dipeptides as endogenous regulators of the activity of sarcoplasmic reticulum Ca-release channels. BBA Biomembranes 1997; 1324: 142-150.

3. Boldyrev AA, Severin SE. The histidine-containing dipeptides, carnosine and anserine: distribution, properties and biological significance. Adv Enzyme Regul 1990; 30: 175-194.

4. Bradley MM, Codispoti M, Cuthbert BN, Lang PJ. Emotion and motivation I: defensive and appetitive reactions in picture processing. Emotion 2001; 1: 276-298.

5. Carrillo E, Moya-Albiol L, González-Bono E, Salvador A, Ricarte J, Gómez-Amor J. Gender differences in cardiovascular and electrodermal responses to public speaking task: the role of anxiety and mood states. Inter J Psychophysiol 2001; 42: 253-264.

6. Chasovnikova LV, Formazuyk VE, Sergienko VI. The anti-oxidative properties of carnosine and other drugs. Biochem Int 1990; 20: 1097-1103.

7. Davey CL. The significance of carnosine and anserine in striated skeletal muscle. Arch Biochem Biophysiol 1960; 89: 303-308.

8. Dawson ME, Schell AM, Filion DL, Berntson GG. The Electrodermal System. Handbook of Psychophysiology. Third edition. New York: Cambridge University Press 2007, p. 159-81.

9. Degroot A, Treit D. Dorsal and ventral hippocampal cholinergic systems modulate anxiety in the plus-maze and shock-probe tests. Brain Res 2002; 949: 60-70.

10. Dolu N, Keloglan S, Bitiktas S, Cug S. The effects of the enriched environment on sympathetic skin response in pentylenetetrazol-kindled rats. Biomed Environ Sci 2013 May; 26(5): 394-7.

11. Dolu N, Yüksek A, Sizer A, Alay M. Arousal and continuous attention during Ramadan intermittent fasting. J Basic Clin Physiol Pharmacol 2007; 18: 315-322.

12. Dolu N. Dose-related anxiogenic effect of glycine in the elevated plus maze and in electrodermal activity. J Basic Clin Physiol Pharmacol 2007; 18: 141-147.

13. Dolu N, Özesmi Ç. Assessment of the dose-dependent effect of tryptophan on anxiety with electrodermal activity and elevated plus maze test in mice. Bulletin of Clinical Psychopharmacology 2007; 17: 74-79.

14. Dunnett M, Harris R. Influence of oral beta-alanine and L-histidine supplementation on the carnosine content of the gluteus medius. Equine Vet J Suppl 1999; 30: 499-504.

15. Edelberg R. Electrical activity of the skin: Its measurement and uses in psychophysiology. In: Greenfield NS., Sternbach RS (Eds), Handbook of Psychophysiology. New York: Holt, Rinehart and Winston 1967, p. 367-418.

16. Fitzpatrick DW, Fisher H. Histamine synthesis, imidazole dipeptides, and wound healing. Surgery 1982; 91: 430-434.

17. Ganong WF. Review of medical physiology. 22nd edition. New York: Lange Medical Books/McGraw-Hill 2005, p. 301-302.

18. Garibella SE, Sinclair AJ. Carnosine; physiological properties and therapeutic potential. Age Ageing 2000; 29: 207-210.

19. Garcia AM, Cardenas FP, Morato S. The effects of pentylenetetrazol, chlordiazepoxide and caffeine in rats tested in the elevated plus-maze depend on the experimental illumination. Behav Brain Res 2011; 217: 171-177.

20. Griebel G, Moreau JL, Jenk F, Martin JR, Mislin R. Some critical determinants of the behaviour of rats in the elevated plus-maze. Behav Processes 1993; 29: $37-48$.

21. Hipkiss AR. Could carnosine or related structures suppress Alzheimer's Disease? Alzheimers Dis 2007; 11: 229-240.

22. Horii Y, Shen J, Fujisaki Y. Effects of 1-carnosine on splenic sympathetic nerve activity and tumor proliferation. Neurosci Lett 2012; 21: 510.

23. Jezova D, Makatsori A, Duncko R, Moncek F, Jakubek M. High trait anxiety in healthy subjects is associated with low neuroendocrine activity during psychosocial stress. Prog. Neuropsychopharmacol Biol Psychiatry 2004; 28: 1331-1336.

24. Jin CL, Yang LX, Wu XH. Effects of carnosine on amygdaloid-kindled seizures in Sprague-Dawley rats. Neuroscience 2005; 135: 939-947.

25. Jin CL, Sakurai E, Kiso Y, Luo JH, Yanai K, Chen Z. Influence of low dietary histamine on seizure development of chemical kindling induced by pentylenetetrazol in rats. Acta Pharmacol Sin 2005; 26: 423-427.

26. Johnson P, Aldstadt J. Effects of carnosine and anserine on muscle and non-muscle phosphorylases. Comp Biochem Physiol 1984; 78: 331-333.

27. Kumar KV, Krishna DR, Palit G. Histaminergic H1 receptors mediate 1-histidine-induced anxiety in elevated plus-maze test in mice. Behav Pharmacol 2007; 18: 213-217.

28. Lister RG. Etiologically based animal models of anxiety disorders. Pharmacol Ther 1990; 46: 321-340.

29. MacFarlane N, McMurray J. Synergism of histidyl dipeptides as antioxidants. J Molec Cell Cardiol 1991; 23: 1205-1207.

30. Marcy R, Quermonne MA, Raoul J, Nammathao B, Smida A. Skin Conductance Reaction (SCR)-Habituation Test, a tool to detect anxiolytic activity. Its justification by the correlation between SCR-Habituation Test activities and specific 
binding potencies in benzodiazepines. Prog. Neuropsychopharmacol. Biol Psychiat 1985; 9: 387-391.

31. Miyata S, Hirano S, Ohsawa M, Kamei J. Chlorpheniramine exerts anxiolytic-like effects and activates prefrontal 5-HT systems in mice. Psychopharmacology 1993; 213: 441-452.

32. Murakami T, Furuse M. The impact of taurine- and beta-alanine-supplemented diets on behavioral and neurochemical parameters in mice: antidepressant versus anxiolytic-like effects. Amino Acids 2010; 39: 427-34

33. Naccache L, Dehaene S, Cohen L, Habert MO, Guichart Gomez E, Galanaud D. Effortless control: executive attention and conscious feeling of mental effort are dissociable. Neuropsychologia 2005; 43: 1318-1328.

34. Nagai K, Tanida M, Niijima A, Tsuruoka N, Kiso Y, Horii Y. Role of L-carnosine in the control of blood glucose, blood pressure, thermogenesis, and lipolysis by autonomic nerves in rats: involvement of the circadian clock and histamine. Amino Acids 2012; 43: 97-109.

35. Nagai K, Niijima A, Yamano T, Otani H, Okumura N, Tsuruoka N, Nakai M, Kiso Y. Possible role of L-carnosine in the regulation of blood glucose through controlling autonomic nerves. Exp Biol Med 2003; 228: 1138-1145.

36. Oprica M, Eriksson C, Schultzberg M. Inflammatory mechanisms associated with brain damage induced by kainic acid with special reference to the interleukin-1 system. J Cell Mol Med 2003; 7: 127-140.

37. Pellow S, Chopin P, File SE, Briley M. Validation of open:closed arm entries in an elevated plus-maze as a measure of anxiety in the rat. J Neurosci Methods 1985; 14: 149-167.

38. Pellow S, File SE. Anxiolytic and anxiogenic drug effects in exploratory activity in an elevated plus-maze. A novel test of anxiety in the rat. Pharmacol Biochem Behav 1986; 24: 525-529.

39. Prast H, Tran MH, Lamberti C, Fischer H, Kraus M, Grass K. Histaminergic neurons modulate acetylcholine release in the ventral striatum: role of $\mathrm{H} 1$ and $\mathrm{H} 2$ histamine receptors. Naunyn. Schmiedebergs. Arch Pharmacol 1999; 360: 552-557.

40. Privou C, Knoche A, Hasenohrl RU, Huston JP. The H1- and H2-histamine blockers chlorpheniramine and ranitidine applied to the nucleus basalis magnocellularis region modulate anxiety and reinforcement related processes. Neuropharmacology 1998; 37: 1019-1032.

41. Quermonne MA, Nammathao B, Louchahi-Raoul J, Marcy R. Skin conductance reaction-habituation test, an elementary model of anxiety as a tool to assess anxiogenic activities of some drugs. Prog. Neuropsychopharmacol. Biol Psychiatry 1993; 17: 311-318
42. Serafim KR, Kishi MS, Canto-de-Souza A, Mattioli R. H1 but not H2 histamine antagonist receptors mediate anxiety-related behaviors and emotional memory deficit in mice subjected to elevated plus-maze testing. Braz J Med Biol Res 2013; 46: $440-446$

43. Shen J, Yao JF, Tanida M, Nagai K. Regulation of sympathetic nerve activity by L-carnosine in mammalian white adipose tissue. Neurosci Lett 2008; 441 $100-104$.

44. Strauman TJ. Self-discrepancies in clinical depression and social phobia: cognitive structures that underlie emotional disorders? J Abnorm. Psychol 1989; 98: $14-22$.

45. Süer C, Dolu N, Ozesmi C, Sahin O, Ulgen A. The relation between skin conductance level and plus-maze behavior in male mice. Physiol Behav 1998; 64: 573-576.

46. Süer C, Dolu N. Electrophysiological evidence of biphasic action of carnosine on long-term potentiation in urethane-anesthetized rats. Neuropeptides $2011 ; 45$ $77-81$.

47. Tanida M, Niijima A. Dose-dependent effects of L-carnosine on the renal sympathetic nerve and blood pressure in urethane-anesthetized rats. Am J Physiol Regul Integr Comp Physiol 2005; 288: 447-455.

48. Tanida M, Gotoh H, Taniguchi H, Otani H, Shen J, Nakamura T. Effects of central injection of L-carnosine on sympathetic nerve activity innervating brown adipose tissue and body temperature in rats. Regul Pept 2007; 144: 62-71.

49. Usui T, Kubo Y, Akanuma SI, Hosoya KI. $\beta$-Alanine and L-histidine transport across the inner blood-retinal barrier: potential involvement in L-carnosine supply. Exp Eye Res 2013; 113: 135-142.

50. Williams LM, Phillips ML, Brammer MJ, Skerrett D, Lagopoulos J. Arousal Dissociates Amygdala and Hippocampal Fear Responses: Evidence from Simultaneous fMRI and Skin Conductance Recording. NeuroImage 2001; 14: 1070-1079.

51. Wu FS, Gibbs TT, Farb DH. Dual activation of GABAA and glycine receptors by beta-alanine: inverse modulation by progesterone and 5 alpha-pregnan- 3 alphaol-20-one. Eur J Pharmacol 1993; 246: 239-246.

52. Vierck CJ, Acosta-Rua AJ, Rossi HL, Neubert JK. Sex Differences in Therma Pain Sensitivity and Sympathetic Reactivity for Two Strains of Rat. J Pain 2008 9: 739-749.

53. Zarrindast MR, Nasehi M, Piri M, Bina P. Anxiety-like behavior induced by histaminergic agents can be prevented by cannabinoidergic WIN55,212-2 injected into the dorsal hippocampus in mice. Pharmacol Biochem Behav 2010; 94 $387-396$

Received: 20/01/2014

Accepted in revised form: 20/08/2014

\section{Corresponding author:}

Prof. Dr. Nazan Dolu, Erciyes University, Faculty of Medicine, Department of Physiology, 38039 Kayseri, Turkey; e-mail: dolu@erciyes.edu.tr; nazan_dolu@yahoo.com 